CIRJE-F-1035

\title{
Does Equalization Transfer Enhance Partial Tax Cooperation?
}

\author{
Wenming Wang \\ Hunan University \\ Keisuke Kawachi \\ Mie University \\ Hikaru Ogawa \\ The University of Tokyo \\ December 2016
}

CIRJE Discussion Papers can be downloaded without charge from:

http://www.cirje.e.u-tokyo.ac.jp/research/03research02dp.html

Discussion Papers are a series of manuscripts in their draft form. They are not intended for circulation or distribution except as indicated by the author. For that reason Discussion Papers may not be reproduced or distributed without the written consent of the author. 


\title{
Does equalization transfer enhance partial tax cooperation?
}

\author{
Wenming Wang \\ Hunan University, China. \\ Keisuke Kawachi \\ Mie University, Japan. \\ Hikaru Ogawa \\ University of Tokyo, Japan.
}

\begin{abstract}
This paper analyzes the effect of equalization transfer scheme on partial tax cooperation condition in a repeated game setting. It is shown that in order to achieve partial tax cooperation between two capital-rich (exporting) countries, the full equalization transfer scheme is superior to the partial equalization transfer scheme, whereas in order to achieve partial tax cooperation between two capital-poor (importing) countries, the partial equalization transfer scheme is superior to the full equalization transfer scheme.
\end{abstract}

Key words: Partial tax cooperation, Full equalization transfer, Partial equalization transfer, Repeated game

\section{Introduction}

The feasibility of partial tax coordination, which requires only a subset of countries agreeing on a harmonized policy, has been extensively studied in the interregional tax competition literature [Burbidge et al (1997), Konrad and Schjelderup (1999), Marchand et al. (2003), Kächelein (2004), Bucovetsky (2009), and Vrijburg and de Mooij (2009)]. ${ }^{1}$ Specifically, it occupies an important place in the tax competition environment with asymmetric regions. Full tax coordination, being the best coordination formula, can be sustained among symmetric regions, but it is difficult to be sustained among asymmetric regions. When the tax competition game is played by asymmetric regions, seeking out the possibility of partial tax coordination is the suboptimal but practical policy agenda. Indeed, a subset of EU members (with a minimum of 8 countries) implements the "Enhanced Cooperation Agreements" (ECA) under the treaties of Amsterdam and Nice, which had been ratified in 1997 and 2003, respectively. The member countries of ECA can coordinate their tax policies, when all the 27 member countries of EU cannot agree on a particular policy issue.

When we study partial tax coordination among asymmetric regions, the interregional equalization transfer cannot be disregarded in both practical and theoretical perspectives. This is

\footnotetext{
${ }^{1}$ Burbige et al. (1997) analyze endogenous coalition formation for capital tax policy and find that grand coalition among all jurisdictions is a unique equilibrium if the number of jurisdictions is only two, which is not the case if there are three or more jurisdictions. Konrad and Schjelderup (1999) show that partial tax cooperation can improve both the welfare of the tax union and that of the outside countries. In contrast, Marchand et al. (2003) show that partial coordination can worsen welfare in some instances and that no coordination should be preferred. Kächelein (2004) demonstrates that the tax union loses from partial tax cooperation when the tax union is small relative to the world market, whereas all countries gain when the tax union is large. Bucovetsky (2009) finds that the residents of all jurisdictions not in the tax union and of the largest jurisdiction in the tax union benefit from partial tax cooperation. In addition, the average pay off of all residents in the tax union increases under partial tax cooperation. Vrijburg and de Mooij (2009) show that tax union member countries increase their tax rates, leading to outside countries gaining from partial tax cooperation. See Keen and Konrad (2013) for a brief review.
} 
attributed to that the intergovernmental equalization transfer as a dominant feature of subnational finance in most societies, amounting to an un-deniable share of government budget, plays the important role in equalizing the outcome of the inherent differences among regions (Boadway and Shah (2007)). It is also known from the theoretical analysis that the introduction of equalization transfer has mixed but significant impacts upon tax coordination: It may foster tax cooperation among asymmetric regions in some cases, but not in other cases (Wang et al. (2014) and Ogawa and Wang (2016)).

The purpose of this paper is to study how the size and the type of equalization transfer scheme determine the feasibility of partial tax coordination. Specifically, this study aims to answer whether countries with partial coordination in their tax policies should let uncoordinated countries join their equalization transfer system. For this, we consider two types of equalization transfer schemes: (i) the full equalization transfer scheme, implemented among not only countries participating tax coordination but also countries which do not join the coordination, and (ii) the partial equalization transfer scheme, implemented between only the member countries of tax coordination. It is known that some countries or regions have incentive to deviate from or had deviated from the policy coordination in the globalized community. Since policy coordination consists of the coordination on multiple policy instruments, the deviation from one policy instrument draws increasing attention on the waves of deviation from the coordination in other policies. Therefore, this paper examines whether full and partial equalization transfer schemes have different effects on the feasibility of partial tax cooperation. By studying this, we aim to find which type of equalization transfer scheme helps to sustain tax coordination. To accomplish this, we employ a three-country model in which two of the three countries form a tax union, as well as consider two cases, where the member countries of the tax union are capital-rich (exporters) or -poor (importers).

Our answer to the question is intriguing: When capital-poor country deviates from tax cooperation and capital-rich countries form tax union to coordinate their tax policy, an increase in the scale of partial equalization transfer is detrimental to partial coordination, and the possibility of partial tax cooperation is higher under full equalization transfer than under partial equalization transfer. This indicates that the full equalization transfer scheme, in which both tax union members and non-members join together, increases the feasibility of partial tax coordination. However, the effects of equalization transfer on partial cooperation condition crucially depend on the net capital exporting position of tax union member countries. Thus, when capital-rich country deviates from tax cooperation and partial tax coordination is conducted between capital-poor countries, an increase in the scale of partial equalization transfer is beneficial to partial tax cooperation, and the possibility of partial tax cooperation is higher under partial equalization transfer than under full equalization transfer. In this case, the exclusion of non-member country of tax union from the equalization transfer scheme increases the feasibility of partial tax coordination between the remaining countries.

As mentioned above, several studies have examined partial tax cooperation. These papers focus on how the partial tax cooperation affects the welfare levels of relative countries. However, they commonly use a static or one-shot framework, wherein partial tax cooperation cannot arise as an endogenous equilibrium. Since there exists fiscal externality in tax policies (Wildasin (1989)), the countries are in the prisoner's dilemma scenario in tax competition. As a result, the cooperation is difficult to maintain in because it is not in the best interest of the individual countries. However, the partial tax cooperation may be endogenously sustained in the long-run since repetition allows countries to punish the deviation of counterpart in the future. This leads us to study the partial tax coordination within a framework of repeated tax competition model. For instance, Itaya et al. (2014) find that partial tax cooperation can be sustained as a subgame perfect Nash equilibrium in a repeated interaction model consisting of symmetric jurisdictions, if the jurisdictions in a coalition group are sufficiently patient. Itaya and Yamaguchi (2015) study the endogenous sequencing of tax policy between coordinated tax union members and non-members. Itaya et al. (2016) analyze the conditions under which partial tax cooperation is sustained in a repeated game with three countries possessing 
asymmetric capital endowments. However, the effect of equalization transfer scheme on partial tax cooperation condition is outside the scope of these papers. ${ }^{2}$ We follow the model of partial tax coordination in repeated game among asymmetric countries; however, the critical feature that differentiates our study is the incorporation of interregional equalization transfer scheme to clarify how it affects the feasibility of partial coordination.

The role of equalization transfer scheme, which is a primary concern of our paper, has also been studied in the tax competition literature. A series of papers by Köthenbürger $(2002,2005,2007)$ studies the effects of interregional transfers on the tax competition equilibrium from the static perspective, and Wang et al. (2014) and Ogawa and Wang (2016) extend the analysis to the dynamic game framework. ${ }^{3}$ Although these studies assume that equalization transfers are implemented among all countries, this paper considers the equalization transfer scheme is implemented among a subset of countries. This enables us to find the different roles of equalization transfer scheme for partial tax coordination, depending on two factors: the sort of country that deviates from tax coordination and the type of equalization transfer scheme.

The remainder of this paper proceeds as follows. Section 2 presents the basic model. Section 3 characterizes the one-shot Nash equilibrium of the model. Section 4 constructs a repeated game setting of partial tax cooperation, in which two countries cooperate with taxation, while another country does not. Lastly, Section 5 concludes the paper.

\section{The model}

The economy comprises three countries $(i=a, b, c)$ that are symmetric except for their heterogeneous capital endowments. It is assumed that three countries have equal population, normalized as 1 in each country. The per capita capital endowment of three countries is $\kappa_{i}$, with $\kappa_{a}+\kappa_{b}+\kappa_{c}=2 \kappa$, where $2 \kappa$ is the total capital endowments of the economy per population. Capital is perfectly mobile across the countries, whereas workers are immobile. These factors are used in the production of a homogenous consumption good. Following Itaya et al. $(2008,2016)$, we assume the production function is given by $f\left(k_{i}\right)=\left(A-k_{i}\right) k_{i}$, where $k_{i}$ is the per capita capital located in country $i$. and $A(>0)$ denotes the production technology parameter which is identical across all countries. We also assume that $A>2 k_{i}$ to ensure the positive marginal productivity of capital.

Private firms are assumed to maximize profits, given by $\pi_{i}=\left(A-k_{i}\right) k_{i}-r k_{i}-t_{i} k_{i}-w_{i}$, where $r$ is the interest rate, $t_{i}$ is the source-based capital tax rates, and $w_{i}$ is the region-specific wage rates. The standard profit-maximizing input choices satisfy $r=A-2 k_{i}-t_{i}$ and $w_{i}=k_{i}^{2}$.

The capital market equilibrium is reached when the sum of per capita capital demands in three countries is equal to the exogenously fixed total capital endowments: $k_{a}+k_{b}+k_{c}=2 \kappa$. In equilibrium, the interest rate and the per capita capital demands of three countries are as follows:

$$
\begin{gathered}
r=A-\frac{4 \kappa}{3}-\frac{t_{a}}{3}-\frac{t_{b}}{3}-\frac{t_{c}}{3} \\
k_{a}=\frac{2 \kappa}{3}-\frac{t_{a}}{3}+\frac{t_{b}}{6}+\frac{t_{c}}{6}
\end{gathered}
$$

\footnotetext{
${ }^{2}$ One of the novelties of these studies is that they depart from the standard approach of full tax coordination in the repeated game models of tax competition. As substitute for full coordination studied by Cardarelli et al. (2002), Taugourdeau (2004), Kawachi and Ogawa (2006), Catenaro and Vidal (2006), Itaya et al. (2008), and Kiss (2012), they examine the feasibility of partial coordination which would be more practical problem.

${ }^{3}$ Wang et al. (2014) prove that when the scale of equalization transfer increases, two symmetric regions become more cooperative to full tax coordination. Ogawa and Wang (2016) show that when the scale of equalization transfer increases, the capital exporting region becomes more cooperative and the capital importing region becomes less cooperative.
} 


$$
\begin{aligned}
& k_{b}=\frac{2 \kappa}{3}-\frac{t_{b}}{3}+\frac{t_{a}}{6}+\frac{t_{c}}{6} \\
& k_{c}=\frac{2 \kappa}{3}-\frac{t_{c}}{3}+\frac{t_{a}}{6}+\frac{t_{b}}{6} .
\end{aligned}
$$

The comparative statics results in $\partial r / t_{i}<0, \partial k_{i} / t_{i}<0$, and $\partial k_{i} / t_{j}>0$

The representative residents of the three countries identically have the utility function of $u_{i}=c_{i}$, where $c_{i}$ is the consumption of private good. They supply one unit of labor to domestic firms and invest their own capital endowments in the home and foreign countries. Accordingly, the budget constraint of a resident in country $i$ is $c_{i}=w_{i}+r \kappa_{i}+g_{i}$, where $r \kappa_{i}$ denotes the capital income and $g_{i}$ represents the lump-sum income transfer from the governments. The lump-sum transfer $g_{i}$ is financed by capital tax revenues $t_{i} k_{i}$ and equalization transfer $\beta_{i}$, implying that the government budget constraint is given by $g_{i}=t_{i} k_{i}+\beta_{i}$.

In the following analysis, without loss of generality, we assume that countries $b$ and $c$ form tax union to coordinate their tax rates, whereas country $a$ deviates from tax coordination and is a non-member of the tax union, choosing its tax rate freely. In this partial tax coordination context, we introduce two types of equalization transfer scheme. First, equalization transfers are made among all three countries, including country $a$, which is referred as the full equalization transfer scheme. Second, equalization transfers are made between only tax union members (countries $b$ and $c$ ), which is referred as the partial equalization transfer scheme. Under this classification, our paper primarily focuses on identifying which type of equalization transfer scheme induces higher possibility of partial tax coordination between countries $b$ and $c$.

Tax base equalization scheme is partly adopted in some countries (e.g., Canada, Denmark, Switzerland, and Australia), thus, we here consider a scheme of that kind, which is conditioned by the difference in tax-base capacity. In each scheme, the government receives equalization transfer based on the gap between the average tax base and the tax base in the country. Therefore, the equalization transfers of each country $i(=a, b, c)$ in the case of full equalization transfer scheme is

$$
\beta_{i}=\theta \times\left(\frac{k_{a}+k_{b}+k_{c}}{3}-k_{i}\right)
$$

where $\theta \in(0,1)$ denotes the scale of equalization transfer. In the case of partial equalization transfer scheme, the equalization transfer scheme is implemented only between two countries $b$ and $c$. Since country $a$ is not included, the equalization transfer of each country is given by

$$
\beta_{a}=0, \quad \beta_{b}=\theta \times\left(\frac{k_{b}+k_{c}}{2}-k_{b}\right) \text { and } \beta_{c}=\theta \times\left(\frac{k_{b}+k_{c}}{2}-k_{c}\right) .
$$

Note that there is no surplus and deficit in both schemes, $\beta_{a}+\beta_{b}+\beta_{c}=0$.

\section{Nash equilibrium}

This section characterizes the Nash equilibrium of the model. To clearly show that the effects of equalization transfer scheme on the possibility of tax coordination critically depend on the sort of country, either capital-rich or capital-poor, form the tax union to coordinate the tax rates, we consider two cases in the subsequent analysis: In case 1, the non-member country $a$ has no initial capital, whereas the other two countries, $b$ and $c$, equally share the total capital in this economy, $\kappa_{a}=0$, $\kappa_{b}=\kappa_{c}=\kappa$. This captures the environment in which capital-rich countries, $b$ and $c$, form the tax union, which competes for mobile capital with capital-poor country $a$. In case 2 , the non-member country $a$ has all the initial capital in the economy, whereas the other two countries, $b$ and $c$, have no 
initial capital endowments, $\kappa_{a}=2 \kappa, \kappa_{b}=\kappa_{c}=0$. This captures the environment in which capital-poor countries $b$ and $c$ form the tax union, which competes for the mobile capital with capital-rich country $a$.

Dividing the analysis into two cases, in this section, we first derive the one-shot Nash equilibrium. In the one-shot tax competition game, we assume that the governments maximize the representative resident's utility with respect to the tax rate, $t_{i}$ :

$$
\operatorname{Max}_{t_{i}} u_{i}=k_{i}^{2}+r \kappa_{i}+t_{i} k_{i}+\beta_{i}
$$

3.1. Case 1: $\kappa_{a}=0, \kappa_{b}=\kappa_{c}=\kappa$

At this point, we consider the first case: all capital is initially owned by countries $b$ and $c$, which will coordinate their tax rates in the next section. Behind this setting, we assume that capital-poor country deviates from tax coordination. Prior to describing the coordinated policy-makings, we present the baseline outcome of one-shot Nash equilibrium. Initially, we derive the Nash equilibrium under the partial equalization transfer scheme. The analysis under the full equalization transfer scheme follows.

Partial equalization transfer scheme. Equalization transfer scheme is implemented only between countries $b$ and $c$. Solving Eq. (5) for $i=a, b, c$ with $\kappa_{a}=0$ and $\kappa_{b}=\kappa_{c}=\kappa$, the Nash equilibrium tax rates in the one-shot tax competition game are as follows:

$$
t_{a}^{N}=\frac{\theta}{6}+\frac{4 \kappa}{9} \text { and } t_{b}^{N}=t_{c}^{N}=\frac{2 \theta}{3}-\frac{2 \kappa}{9}
$$

where the superscript $N$ denotes the one-shot Nash equilibrium. Inserting Eq. (6) into Eqs. (1)-(4), we obtain the respective net capital return and capital demand in each country:

$$
r^{N}=A-\frac{\theta}{2}-\frac{4 \kappa}{3}, k_{a}^{N}=\frac{4 \kappa}{9}+\frac{\theta}{6} \text { and } k_{b}^{N}=k_{c}^{N}=\frac{7 \kappa}{9}-\frac{\theta}{12}
$$

Given that country $a$ has no initial capital, this equation shows that country $a$ is the capital importer, whereas countries $b$ and $c$ are the capital exporters. Using equilibrium values, the utility levels of the three countries in the Nash equilibrium can be derived as follows:

$$
u_{a}^{N}=\frac{32 \kappa^{2}}{81}+\frac{\theta \kappa}{8}+\frac{\theta^{2}}{18} \text { and } u_{b}^{N}=u_{c}^{N}=A \kappa-\frac{73 \kappa^{2}}{81}-\frac{5 \theta \kappa}{54}-\frac{7 \theta^{2}}{144}
$$

Full equalization transfer scheme. Next, we derive the equilibrium under full equalization transfer scheme, in which equalization transfers are made among three countries. In this case, we obtain the one shot game Nash equilibrium tax rates as follows:

$$
t_{a}^{N}=\theta+\frac{4 \kappa}{9} \text { and } t_{b}^{N}=t_{c}^{N}=\theta-\frac{2 \kappa}{9}
$$

Substituting Eq. (8) into Eqs. (1)-(4), we have the respective net capital return and capital demands of three countries:

$$
r^{N}=A-\theta-\frac{4 \kappa}{3}, k_{a}^{N}=\frac{4 \kappa}{9} \text { and } k_{b}^{N}=k_{c}^{N}=\frac{7 \kappa}{9} .
$$


Country $a$ is still a capital importer, whereas countries $b$ and $c$ are still capital exporters. Using the equilibrium values, we obtain the following utility levels of the three countries in the Nash equilibrium:

$$
u_{a}^{N}=\frac{32 \kappa^{2}}{81}+\frac{2 \theta \kappa}{3} \text { and } u_{b}^{N}=u_{c}^{N}=A \kappa-\frac{73 \kappa^{2}}{81}-\frac{\theta \kappa}{54}
$$

3.2. Case 2: $\kappa_{a}=2 \kappa, \kappa_{b}=\kappa_{c}=0$

We now consider the case in which countries $b$ and $c$ have no initial capital, whereas country $a$ owns all capital endowments.

Partial equalization transfer scheme. Assuming that only countries $b$ and $c$ take part in the equalization transfer scheme, the one shot Nash equilibrium tax rates of the three countries are as follows:

$$
t_{a}^{N}=\frac{\theta}{6}-\frac{8 \kappa}{9} \text { and } t_{b}^{N}=t_{c}^{N}=\frac{2 \theta}{3}+\frac{4 \kappa}{9} .
$$

Inserting Eq.(10) into Eqs.(1)-(4), we obtain the net capital return and the capital demands of three countries:

$$
r^{N}=A-\frac{\theta}{2}-\frac{4 \kappa}{3}, k_{a}^{N}=\frac{10 \kappa}{9}+\frac{\theta}{6} \text { and } k_{b}^{N}=k_{c}^{N}=\frac{4 \kappa}{9}-\frac{\theta}{12}
$$

As expected, country $a$ is a capital exporter, whereas countries $b$ and $c$ are capital importers. Using the values in the equilibrium, we derive the following utility levels of the three countries in the Nash equilibrium:

$$
u_{a}^{N}=A \kappa-\frac{196 \kappa^{2}}{81}-\frac{16 \theta \kappa}{27}+\frac{\theta^{2}}{18} \text { and } u_{b}^{N}=u_{c}^{N}=\frac{32 \kappa^{2}}{81}+\frac{5 \theta \kappa}{27}-\frac{7 \theta^{2}}{144}
$$

Full equalization transfer scheme. All three countries take part in the equalization transfer scheme. The Nash equilibrium tax rates of the one-shot tax competition are:

$$
t_{a}^{N}=\theta-\frac{8 \kappa}{9} \text { and } t_{b}^{N}=t_{c}^{N}=\theta+\frac{4 \kappa}{9}
$$

Using Eq.(12) with Eqs. (1)-(4), we obtain the net capital return and the capital demands of the three countries as follows:

$$
r^{N}=A-\theta-\frac{4 \kappa}{3}, k_{a}^{N}=\frac{10 \kappa}{9} \text { and } k_{b}^{N}=k_{c}^{N}=\frac{4 \kappa}{9},
$$

which shows that country $a$ is still a capital exporter, while countries $b$ and $c$ are capital importers. We then obtain the following utility levels of the three countries in the Nash equilibrium:

$$
u_{a}^{N}=2 A \kappa-\frac{196 \kappa^{2}}{81}-\frac{4 \theta \kappa}{3} \text { and } u_{b}^{N}=u_{c}^{N}=\frac{32 \kappa^{2}}{81}+\frac{2 \theta \kappa}{3} \text {. }
$$


Before considering the partial cooperative outcome, we summarize the common characteristics of Nash equilibrium in each case.

Lemma 1. (i) In the absence of equalization transfer scheme $(\theta=0)$, capital-poor (-importing) countries chooses larger tax rate than that in capital-rich (-exporting) countries. (ii) The presence of equalization transfer scheme increases the tax rates set by three countries.

Proof. (i) Assume $\theta=0 . t_{b}^{N}=t_{c}^{N}<t_{a}^{N}$ in Eqs. (6) and (8). In addition, $t_{b}^{N}=t_{c}^{N}>t_{a}^{N}$ in Eqs. (10) and (12). (ii) From Eqs. (6), (8), (10), and (12), $\partial t_{i}^{N} / \partial \theta>0$. (Q.E.D.)

The first argument is based on that countries tend to manipulate the terms of trade (price of capital) in their policy settings. Countries which import capital prefer low price of capital to reduce payment for capital borrowing, whereas capital exporting countries prefer high capital price to increase the return from capital investment. As $\partial r / \partial t_{i}<0$, capital-importing countries set higher tax rates and capital-exporting countries choose lower tax rates. The second argument, which implies that the both types of equalization transfer scheme mitigate the tax-cut competition, stems from the equalization transfer effect: the governments lose a part of their revenues under the equalization transfer scheme when they attract more capital investment, which lowers the incentive for governments to competing for capital by reducing their tax rates.

\section{Partial cooperation in the repeated game}

In this section, we investigate the conditions under which partial tax cooperation is sustained. We suppose that countries $b$ and $c$ agree to cooperate on the setting of their common tax rates by forming tax union, whereas country $a$ does not join the coordination and chooses its tax rate non-cooperatively. The tax union maximizes the sum of their utilities with respect to $t_{b}$ and $t_{c}$ :

$$
\operatorname{Max}_{t_{b}, t_{c}} u_{b}+u_{c}=k_{b}^{2}+k_{c}^{2}+r \kappa_{b}+r \kappa_{c}+t_{b} k_{b}+t_{c} k_{c}+\beta_{b}+\beta_{c}
$$

The outside country $a$ chooses its tax rate to maximize its own utility non-cooperatively and independently, behaving in accordance with Eq. (5). By solving these problems and deriving the best-response functions simultaneously, we obtain the cooperative tax rates by the partial tax union, denoted by $t_{b}^{C}, t_{c}^{C}$, and the tax rate chosen by the non-member country $a, t_{a}^{C}$, in the subgroup Nash equilibrium. Substituting $t_{i}^{C}$ into Eqs. (1)-(4) for all $i$, we can derive the net return of capital $r^{C}$ and the demands of capital in country $i, k_{i}^{C}$ in the cooperative phase. Using $t_{i}^{C}, r^{C}$, and $k_{i}^{C}$, we obtain the utility levels of the tax and non-tax union member countries, $u_{a}^{C}, u_{b}^{C}$, and $u_{c}^{C}$.

Furthermore, the best-deviation tax rates of tax union member countries, $t_{i}^{D}(i=b, c)$, are chosen by maximizing $u_{i}$ given $t_{j}=t_{j}^{C}(j=c, b, j \neq i)$ and $t_{a}=t_{a}^{C}$. Substituting $t_{i}^{D}, t_{j}^{C}$, and $t_{a}^{C}$, into Eqs. (1)-(4), we get the net return of capital $r^{D}$ and the demands of capital $k_{i}^{D}, k_{j}^{D}, k_{a}^{D}$ in the deviation phase, where $k_{j}^{D}$ denotes the amount of capital in country $j(j=c, b, j \neq i)$ when country $i$ deviates from tax coordination. As a result, the utility levels of deviation, $u_{i}^{D}(i=b, c)$, can be derived.

The discount factors of tax union member countries are $\delta_{i}(i=b, c)$. We assume that in every period each tax union member country sets its tax rate at $t_{i}^{C}$, on the condition that the other tax union member country has followed it in the previous period. If one tax union member country deviates, the partial tax cooperation of the tax union collapses, triggering the punishment phase (Nash equilibrium) to persist infinitely. To sustain the partial tax cooperation in the tax union, the following condition is required: 


$$
\frac{1}{1-\delta_{i}} u_{i}^{C} \geq u_{i}^{D}+\frac{\delta_{i}}{1-\delta_{i}} u_{i}^{N}
$$

where $i=b, c$ and $u_{i}^{h}$ for $h=C, D, N$ represent the utility levels in the partial cooperation, deviation, and punishment phases, respectively. The left-hand side of Eq. (14) denotes the total discounted utility of representative resident in country $i$, when partial tax cooperation is sustained infinitely. The right-hand side of Eq. (15) denotes the sum of the current period deviation utility and the total discounted value of utility under the punishment phase in all subsequent periods.

Based on Eq. (15), we obtain the minimum discount factor of the tax union member $(i=b, c)$ countries that ensures the partial coordination, as follows:

$$
\delta_{i}=\frac{u_{i}^{D}-u_{i}^{C}}{u_{i}^{D}-u_{i}^{N}}
$$

Only the actual discount factors of both tax union member countries exceed any of $\delta_{i}(i=b, c)$, given by Eq. (16), the partial tax cooperation in the tax union can be sustained as a subgame perfect Nash equilibrium of the repeated game.

\subsection{Case 1: Capital-rich countries form the tax union $\left(\kappa_{a}=0, \kappa_{b}=\kappa_{c}=\kappa\right)$}

We initially consider the case in which partial cooperation is made between two capital-rich (exporting) countries, that is, the tax union consists of countries $b$ and $c$, with country $a$ outside the tax union. ${ }^{4}$

Partial equalization transfer scheme. Assuming $\kappa_{a}=0$ and $\kappa_{b}=\kappa_{c}=\kappa$, the cooperative tax rates of the tax union member countries $b$ and $c$ are obtained by maximizing Eq. (14), subject to $\beta_{b}+\beta_{c}=0$ under partial equalization transfer scheme. Country $a$ simply maximizes Eq. (5). The tax rates in partial coordination phase can be obtained as follows:

$$
t_{b}^{C}=t_{c}^{C}=-\frac{2 \kappa}{3} \text { and } t_{a}^{C}=\frac{\kappa}{3}
$$

implying that countries $b$ and $c$ export capital with subsidies, whereas country $a$ imports capital with taxes. Note that tax rates do not depend on the scale of partial equalization transfer scheme, $\theta$, because there is not any effect of the partial equalization transfer scheme in the maximization problem of tax union under partial tax cooperation, $\beta_{b}+\beta_{c}=0$.

When country $i(i=b, c)$ deviates from the tax coordination, keeping country $j$ 's $(j \neq i)$ tax rate at $t_{j}^{C}$, we obtain the tax rates in the deviation phase:

$$
t_{i}^{D}=\frac{9 \theta}{16}-\frac{7 \kappa}{24}, t_{j}^{C}=-\frac{2 \kappa}{3}, \text { and } t_{a}^{C}=\frac{\kappa}{3}
$$

Comparing the tax rates in the cooperative phase, $t_{i}^{C}$, and deviation phase, $t_{i}^{D}$, we find that country $i$ $(i=b, c)$, which deviates from the partial tax coordination, increases its tax rate $\left(t_{i}^{D}>t_{i}^{C}\right)$. There are two routes that explain the tax increase in deviation phase. First, when capital-rich countries form the tax union, the member countries coordinate their tax rates at lower level to increase the capital price. However, each member country has incentive to deviate from coordination by increasing its tax rate,

\footnotetext{
${ }^{4}$ By calculating relative minimum discount factors, we have confirmed that partial tax cooperation between countries $a$ and $b$ and partial tax cooperation between countries $a$ and $c$ are not feasible.
} 
which brings about higher tax revenue. Second, the equalization transfer effect prevails in the deviation phase (but not in the cooperation phase), inducing the country which deviates from tax coordination chooses higher tax rate.

Using above tax rates, we have the equilibrium capital allocation, capital prices, and utility levels in each phase. To have a relevant equilibrium, the participation constrain conditions $u_{i}^{C}>u_{i}^{N}$ for tax union member country $i(=b, c)$ are required. The utility of countries $b$ and $c$ in the cooperative phase is given by $u_{b}^{C}=u_{c}^{C}=A \kappa-31 \kappa^{2} / 36$ (see Appendix A). With $u_{i}^{N}$ in (7), we confirm that the participation constraint conditions are satisfied:

$$
u_{i}^{C}-u_{i}^{N}=\frac{13 \kappa^{2}}{324}+\frac{5 \theta \kappa}{27}+\frac{7 \theta^{2}}{144}>0
$$

Inserting the equilibrium utility levels into Eq. (16), we derive the minimum discount factors of the tax union member countries $b$ and $c$ as follows (see Appendix B):

$$
\delta_{i}^{r p}=\frac{81(3 \theta+2 \kappa)^{2}}{736 \kappa^{2}+1932 \theta \kappa+1233 \theta^{2}} \in(0,1) \text { for } \theta>0 \text { and } \kappa>0,
$$

where $\delta_{i}^{r p}(i=b, c)$ denotes the minimum discount factor of country $i$ that supports the partial coordination between the two capital-rich countries under partial equalization transfer scheme. A superscript " $r p$ " denotes the capital-rich countries and the partial equalization transfer scheme. Differentiating the minimum discount factors with the scale of partial equalization transfer, $\theta$, we obtain:

$$
\frac{\partial \delta_{i}^{r p}}{\partial \theta}=\frac{1944 \kappa(2 \kappa+3 \theta)(23 \kappa+36 \theta)}{\left(736 \kappa^{2}+1932 \theta \kappa+1233 \theta^{2}\right)^{2}}>0 .
$$

We have:

Lemma 2. When the scale of partial equalization transfer $\theta$ increases, the two capital-rich (exporting) countries become less cooperative to partial tax cooperation.

To explain the result, we consider how the change in the scale of equalization transfer, $\theta$, affects the incentive for deviation. Thus, we differentiate $u_{i}^{D}(i=b, c)$ with respect to $\theta$ :

$$
\frac{\partial u_{i}^{D}}{\partial \theta}=\underbrace{\frac{\partial\left(k_{i}^{D}\right)^{2}}{\partial \theta}}_{\text {wage effect }}+\underbrace{\kappa \frac{\partial r^{D}}{\partial \theta}}_{\text {capital return effect }}+\underbrace{\left(k_{i}^{D} \frac{\partial t_{i}^{D}}{\partial \theta}+t_{i}^{D} \frac{\partial k_{i}^{D}}{\partial \theta}\right)}_{\text {tax revenue effect }}+\underbrace{\theta \frac{\partial\left(\frac{k_{i}^{D}+k_{j}^{D}}{2}-k_{i}^{D}\right)}{\partial \theta}}_{\text {transfer base effect }}+\underbrace{\left(\frac{k_{i}^{D}+k_{j}^{D}}{2}-k_{i}^{D}\right)}_{\text {transfer scale effect }} .
$$

The first-order derivative can be broken down into the wage, capital return, tax revenue, equalization transfer base and equalization transfer scale effects. Since first four terms are non-extant, only the equalization transfer scale effect remains (see Appendix C):

$$
\frac{\partial u_{i}^{D}}{\partial \theta}=\left(\frac{k_{i}^{D}+k_{j}^{D}}{2}-k_{i}^{D}\right)=\frac{1}{2}\left(k_{j}^{D}-k_{i}^{D}\right)=\frac{3 \kappa}{32}+\frac{9 \theta}{64}>0,
$$


where $i=b, c, j=c, b, j \neq i$. As explained, when country $i$ deviates from partial tax coordination, the deviation tax rate of country $i$, $t_{i}^{D}$, in Eq. (18) is higher than the cooperative tax rate of country $i$, $t_{i}^{C}$, in Eq. (17), $t_{i}^{C}<t_{i}^{D}$. This means that the tax base of tax union member country $i(=b, c)$, which deviates from tax coordination, is smaller than that of the other tax union member country $j(=c, b)$, $\left(k_{i}^{D}<k_{j}^{D}\right)$. The equalization transfer scale effect then is positive, indicating that when the scale of partial equalization transfer $\theta$ increases, country $i$ will have stronger incentive to deviate. Thus, when the scale of partial equalization transfer $\theta$ increases, country $i$ will have weaker incentive for partial tax cooperation.

Full equalization transfer scheme. In the partial cooperation phase, countries $b$ and $c$ maximize Eq. (14) and country $a$ maximizes Eq. (5). The tax rates are

$$
t_{b}^{C}=t_{c}^{C}=-\frac{2 \kappa}{3}+\theta \text { and } t_{a}^{C}=\frac{\kappa}{3}+\theta
$$

Since the tax union is not subjected to $\beta_{b}+\beta_{c}=0$ in their optimization problem under the full equalization transfer scheme, the cooperative tax rates depend on $\theta$. Comparing Eq. (17) and Eq. (21), it is found that tax rates in the partial cooperation phase under the full equalization transfer scheme are larger than that under the partial equalization transfer scheme. This is because all counties under the full equalization transfer scheme take into account the equalization transfer effect in their tax settings.

When country $i(i=b, c)$ deviate from the tax coordination, keeping country $j$ 's $(j \neq i)$ tax rates at $t_{j}^{C}$, we obtain the tax rates in the deviation phase:

$$
t_{i}^{D}=-\frac{7 \kappa}{24}+\theta, t_{j}^{C}=-\frac{2 \kappa}{3}+\theta, \text { and } t_{a}^{C}=\frac{\kappa}{3}+\theta
$$

where $i=b, c, j=c, b, j \neq i$. As in the case of partial equalization transfer scheme, country $i$ increases its tax rate when it deviates from partial tax cooperation. Using tax rates in each phase again, we derive the capital demands, capital price, and utility levels. We can confirm that the participation constraints always hold: $u_{i}^{C}-u_{i}^{N}=13 \kappa^{2} / 324>0$ for $i=b, c$.

The minimum discount factors for the coordination between capital-rich countries $b$ and $c$ under the full equalization transfer scheme, $\delta_{i}^{r f}$, are simply given as follows (see Appendix D):

$$
\delta_{i}^{r f}=\frac{81}{184}
$$

where superscript " $r f$ " denotes the partial coordination between capital-rich countries under the full equalization transfer scheme. Comparing Eq. (19) with Eq. (23), we obtain the following result:

Proposition 1. To achieve partial tax cooperation between two capital-rich (exporting) countries, the full equalization transfer scheme is superior to the partial equalization transfer scheme: $\delta_{i}^{r p}>\delta_{i}^{r f}$.

Proof. Using Eqs. (19) and (23), we have:

$$
\delta_{i}^{r p}-\delta_{i}^{r f}=\frac{243 \theta(141 \theta+92 \kappa)}{736 \kappa^{2}+1932 \kappa \theta+1233 \theta^{2}}
$$

showing that $\delta_{i}^{r p}>\delta_{i}^{r f}$. (Q.E.D) 
Proposition 1 shows the superiority of the full equalization transfer scheme for the partial tax cooperation between two capital-rich (exporting) countries. The intuition of this result can be explained by considering the incentive to deviate from the tax coordination. The deviation tax rates under the full equalization transfer scheme, $t_{i}^{D}$ in Eq. (22), are higher than those under the partial equalization transfer scheme, $t_{i}^{D}$ in Eq. (18). This is because cooperative tax rates under full equalization transfer scheme, $t_{i}^{C}$ in Eq. (21), are higher than those under the partial equalization transfer scheme, $t_{i}^{C}$ in Eq. (17). Given the negative relationship of the net capital return and tax rates, the net capital return in the deviation phase under the partial equalization transfer is higher than that under the full equalization transfer. Since capital exporting countries prefer higher net capital return to receive higher capital income, the deviation incentive of the two capital exporting countries under the partial equalization transfer is larger than that under the full equalization transfer. As a result, the possibility of partial tax cooperation between the two capital exporting countries under the partial (full) equalization transfer scheme is relatively lower (higher).

\subsection{Case 2: Capital-poor countries form the tax union $\left(\kappa_{a}=2 \kappa, \kappa_{b}=\kappa_{c}=0\right)$}

The tax union still consists of countries $b$ and $c$, with country $a$ outside the tax union. However, we now consider the case in which partial cooperation is made between two capital-poor (importing) countries. ${ }^{5}$

Partial equalization transfer scheme. Assuming $\kappa_{a}=2 \kappa$ and $\kappa_{b}=\kappa_{c}=0$, the cooperative tax rates of the tax union member countries $b$ and $c$ are obtained by maximizing Eq. (14), subject to $\beta_{b}+\beta_{c}=0$ under partial equalization transfer scheme. Country $a$ simply maximizes Eq. (5). Solving the problems, we obtain the cooperative tax rates as follows:

$$
t_{b}^{C}=t_{c}^{C}=\frac{4 \kappa}{3} \text { and } t_{a}^{C}=-\frac{2 \kappa}{3}
$$

Again, the cooperative tax rates do not depend on $\theta$.

When country $i(i=b, c)$ deviates from the tax coordination, keeping country $j$ 's $(j \neq i)$ tax rate at $t_{j}^{C}$, we obtain the tax rates in the deviation phase:

$$
t_{i}^{D}=\frac{9 \theta}{16}+\frac{7 \kappa}{12}, t_{j}^{C}=\frac{4 \kappa}{3}, \text { and } t_{a}^{C}=-\frac{2 \kappa}{3}
$$

We make the following assumption which ensures that, as explained later, the participation constraint conditions are satisfied (see Appendix E):

\section{Assumption 1. $4 \kappa>3 \theta$.}

Comparing the tax rates in the cooperative phase, $t_{i}^{C}$ in Eq. (24) and in the deviation phase, $t_{i}^{D}$ in Eq. (25) for $i=b, c$, under Assumption 1, we find country $i(i=b, c)$, which deviates from the partial coordination, decreases it's tax rate, $t_{i}^{C}>t_{i}^{D}$. The reason of tax-cut in the deviation phase, can be explained as follows. When capital-poor countries form the tax union, the member countries coordinate their tax rates at high level to lower the capital price. In this coordination, however, each member country has deviation incentive to decrease its tax rate to attract capital inflow. Although

\footnotetext{
${ }^{5}$ As in case 1, we have confirmed that partial tax cooperation between countries $a$ and $b$ and partial tax cooperation between countries $a$ and $c$ are not feasible.
} 
there is the equalization transfer effect, which works in the direction towards an increase in the tax rates, it is reversed by the tax-cut incentive in the deviation phase under Assumption 1.

Using the tax rates in Eqs. (24) and (25), we derive the capital demands, capital prices, and utility levels in each phase. To obtain relevant equilibrium, it is required to satisfy the participation constraint conditions $u_{i}^{C}>u_{i}^{N}$ for tax union member country $i(=b, c)$. They are satisfied under Assumption 1.

In a similar manner with Section 4.1, we derive the minimum discount factors for tax coordination between capital-poor countries under the partial equalization transfer scheme, $\delta_{i}^{p p}$, as follows:

$$
\delta_{i}^{p p}=\frac{81(4 \kappa-3 \theta)}{185(4 \kappa-3 \theta)+144 \theta} .
$$

Note that $0<\delta_{i}^{p p}<1$ under Assumption 1. By partially differentiating Eq. (26) with the scale of partial equalization transfer, $\theta$, we obtain

$$
\frac{\partial \delta_{i}^{p p}}{\partial \theta}=-\frac{46656 \kappa}{(411 \theta-740 \kappa)^{2}}<0
$$

Thus, we have

Lemma 3. When the scale of partial equalization transfer $\theta$ increases, the two capital-poor (importing) countries become more cooperative to partial tax cooperation.

This result is quite contrasting to Lemma 2. To understand the mechanism behind this result, we differentiate $u_{i}^{D}$ with respect to $\theta$ in order to clarify the incentive for deviation:

$$
\frac{\partial u_{i}^{D}}{\partial \theta}=\underbrace{\frac{\partial\left(k_{i}^{D}\right)^{2}}{\partial \theta}}_{\text {wage effect }}+\underbrace{\left(k_{i}^{D} \frac{\partial t_{i}^{D}}{\partial \theta}+t_{i}^{D} \frac{\partial k_{i}^{D}}{\partial \theta}\right)}_{\text {tax revenue effect }}+\underbrace{\theta \frac{\partial\left(\frac{k_{i}^{D}+k_{j}^{D}}{2}-k_{i}^{D}\right)}{\partial \theta}}_{\text {transfer base effect }}+\underbrace{\left(\frac{k_{i}^{D}+k_{j}^{D}}{2}-k_{i}^{D}\right)}_{\text {transfer scale effect }}
$$

The derivative of $u_{i}^{D}$ with respect to $\theta$ can be broken down into the wage, tax revenue, equalization transfer base and equalization transfer scale effects. Note that there is no capital return effect as countries $b$ and $c$ have no capital endowments. The first three terms are neutralized, and that only the equalization transfer scale effect remains (see Appendix F):

$$
\frac{\partial u_{i}^{D}}{\partial \theta}=\left(\frac{k_{i}^{D}+k_{j}^{D}}{2}-k_{i}^{D}\right)=\frac{1}{2}\left(k_{j}^{D}-k_{i}^{D}\right)=-\frac{9 \alpha}{64}\left(\frac{4 \kappa}{3}-\theta\right)<0,
$$

where $i=b, c, j=c, b, j \neq i$. Assumption 1 ensures the inequality. As mentioned, due to the tax-cut incentive of countries, the deviation tax rates are smaller than the cooperation tax rates. This implies that in the deviation phase the tax base of country $i(=b, c)$, which deviates from the tax coordination, is larger than that of the other tax union member country $j(=c, b)$. This induces a negative transfer scale effect. Overall, when the scale of partial equalization transfer scheme $\theta$ increases, the deviation incentives of countries $b$ and $c$ decrease. The two capital importing countries then become more cooperative as the scale of partial equalization transfer scheme $\theta$ increases. 
Full equalization transfer scheme. In the partial cooperation phase, countries $b$ and $c$ maximize Eq. (14) and country $a$ maximizes Eq. (5). The tax rates are

$$
t_{b}^{C}=t_{c}^{C}=\frac{4 \kappa}{3}+\theta \text { and } t_{a}^{C}=-\frac{2 \kappa}{3}+\theta
$$

Comparing Eq. (24) and Eq. (28), it can be found that the cooperative tax rates under the full equalization transfer scheme are again larger than those under the partial equalization transfer scheme.

When country $i(i=b, c)$ deviates from the tax coordination, keeping country $j$ 's $(j \neq i)$ tax rate at $t_{j}^{C}$, we obtain the tax rates in the deviation phase:

$$
t_{i}^{D}=\frac{7 \kappa}{12}+\theta, t_{j}^{C}=\frac{4 \kappa}{3}+\theta, \text { and } t_{a}^{C}=-\frac{2 \kappa}{3}+\theta
$$

Comparing Eq. (28) and Eq. (29), under the full equalization transfer scheme country $i(i=b, c)$ decreases its tax rate when it deviates from partial cooperation. It is opposite to the case in which two capital-rich countries form the tax union. This can still be attributed to that all countries take into account the equalization transfer effect in their tax settings under the full equalization transfer scheme.

The minimum discount factors for tax coordination between capital-poor countries, $b$ and $c$, under full equalization transfer scheme, $\delta_{i}^{p f}$, is simply given as:

$$
\delta_{i}^{p f}=\frac{81}{185}, i=b, c .
$$

Comparing Eq. (26) with Eq. (30), we have the following result:

Proposition 2. To achieve partial tax cooperation between two capital-poor (importing) countries, the partial equalization transfer scheme is superior to the full equalization transfer scheme: $\delta_{i}^{p p}<\delta_{i}^{p f}$.

Proof. The comparison gives

$$
\delta_{i}^{p p}-\delta_{i}^{p f}=-\frac{11664 \theta}{185[185(4 \kappa-3 \theta)+144 \theta]}
$$

Under Assumption 1, we have $\delta_{i}^{p p}<\delta_{i}^{p f}$.

Proposition 2, showing the superiority of the partial equalization transfer scheme for partial tax cooperation between two capital-poor (importing) countries, is quite contrasting to Proposition 1 . The intuitive explanation for this result can be given by considering the incentive to deviate from the tax coordination between capital-poor countries as well. From Eq. (25) and Eq. (29), we find that the deviation tax rates under the partial equalization transfer scheme are smaller than those under the full equalization transfer scheme, implying that in the deviation phase the net capital return under the partial equalization transfer scheme is higher than that under the full equalization transfer scheme. Given that capital importing countries prefer lower net capital return, two capital importing countries face larger deviation incentives under the full equalization transfer scheme. As a result, the 
possibility of partial tax cooperation between two capital importing countries is higher (lower) under the partial (full) equalization transfer scheme.

\section{Conclusion}

In this paper, we study whether the deviation from tax coordination by a country leads or should lead to deviation from the coordination in other policy instruments in order to keep the tax coordination among the remaining countries. After the Great Britain's departure from the EU, it becomes a very interesting question to consider whether Brexit leads to a deviation from EU equalization transfer scheme for UK.

Motivated by this historical event, we constructed a three-country model of repeated tax competition in which two symmetric countries partially cooperate with tax policies and one country is not affiliated with the tax union. We demonstrated that the feasibility of partial tax coordination critically depends on the type of equalization transfer scheme and the net capital-exporting position of tax union member countries. When partial tax coordination is formed among capital-rich (-exporting) countries, the full equalization transfer scheme, which consists of both the tax union members and the non-member country, is beneficial to the partial tax cooperation. In contrast, when the partial tax coordination is implemented by capital-poor (-importing) countries, then partial equalization transfer scheme, which consists of only the tax union member countries, is beneficial to the partial tax cooperation. Based on this result, we can suggest that whether the equalization transfer scheme among tax union members should be applied to non-members depends on whether the country that deviates from the tax coordination is capital-rich or -poor.

\section{Appendices}

Appendix A. In the partial cooperation phase with partial equalization transfer between country $b$ and $c$, we obtain $t_{b}^{C}=t_{c}^{C}=-2 \kappa / 3$ and $t_{a}^{C}=\kappa / 3$. Substituting $t_{i}^{C}$ into Eqs. (1)-(4), we have $k_{b}^{C}=k_{c}^{C}=5 \kappa / 6, k_{a}^{C}=\kappa / 3$, and $r^{C}=A-\kappa$, which are used to get

$$
u_{b}^{C}=u_{c}^{C}=A \kappa-\frac{31 \kappa^{2}}{36}
$$

Appendix B. When country $i(i=b, c)$ deviates from the coordination, we obtain:

$$
\begin{gathered}
t_{i}^{D}=\frac{9 \theta}{16}-\frac{7 \kappa}{24}, t_{j}^{C}=-\frac{2 \kappa}{3}, t_{a}^{C}=\frac{\kappa}{3}, k_{i}^{D}=\frac{51 \kappa}{72}-\frac{3 \theta}{16}, k_{j}^{D}=\frac{43 \kappa}{48}+\frac{3 \theta}{32}, \\
r^{D}=A-\frac{9 \kappa}{8}-\frac{3 \theta}{16} \text { and } u_{i}^{D}=A \kappa-\frac{239 \kappa^{2}}{288}+\frac{3 \theta \kappa}{32}+\frac{9 \theta^{2}}{128}
\end{gathered}
$$

where $i=b, c, j=c, b, j \neq i$. Inserting $u_{i}^{N}$ in Eq. (9), $u_{i}^{C}$ in Eq. (A1) and $u_{i}^{D}$ in (A2) for $i=b, c$ into Eq. (16), we obtain Eq. (19).

Appendix C. Using Eq. (A2), we have

$$
\begin{aligned}
& \frac{\partial\left(k_{i}^{D}\right)^{2}}{\partial \theta}=\frac{9 \theta}{128}-\frac{7 \kappa}{64}, \quad \kappa \frac{\partial r^{D}}{\partial \theta}=-\frac{3 \kappa}{16}, \quad \theta \frac{\partial\left(\frac{k_{i}^{D}+k_{j}^{D}}{2}-k_{i}^{D}\right)}{\partial \theta}=\frac{9 \theta}{64}, \\
& k_{i}^{D} \frac{\partial t_{i}^{D}}{\partial \theta}+t_{i}^{D} \frac{\partial k_{i}^{D}}{\partial \theta}=\frac{29 \kappa}{64}-\frac{27 \theta}{128}, \quad \text { and }\left(\frac{k_{i}^{D}+k_{j}^{D}}{2}-k_{i}^{D}\right)=\frac{3 \kappa}{32}+\frac{9 \theta}{64} .
\end{aligned}
$$


Then, we get

$$
\frac{\partial k_{i}^{2}}{\partial \theta}+\kappa \frac{\partial r^{D}}{\partial \theta}+\theta \frac{\partial\left(\frac{k_{i}^{D}+k_{j}^{D}}{2}-k_{i}^{D}\right)}{\partial \theta}+k_{i}^{D} \frac{\partial t_{i}^{D}}{\partial \theta}+t_{i}^{D} \frac{\partial k_{i}^{D}}{\partial \theta}=0,
$$

which is used to derive Eq. (20).

Appendix D. In the full coordination phase, we obtain $t_{b}^{C}=t_{c}^{C}=\theta-(2 \kappa / 3)$ and $t_{a}^{C}=\theta+(\kappa / 3)$. Substituting $t_{i}^{C}$ into Eqs. (1)-(4), we have $k_{b}^{C}+k_{c}^{C}=5 \kappa / 6, k_{a}^{C}=\kappa / 3$, and $r^{C}=A-\kappa-\theta$, which are used to have

$$
u_{b}^{C}=u_{c}^{C}=A \kappa-\frac{31 \kappa^{2}}{36}-\frac{\kappa \theta}{3}
$$

When country $i(i=b, c)$ deviates from tax coordination, we obtain $t_{i}^{D}=\theta-(7 \kappa / 24), t_{j}^{C}=\theta-$ $(2 \kappa / 3)$, and $t_{a}^{C}=\theta+(\kappa / 3)$ in the deviation phase. Using these tax rates, we have $k_{i}^{D}=$ $51 \kappa / 72, k_{j}^{D}=43 \kappa / 48$, and $r^{D}=A-\theta-(9 \kappa / 8)$. Then, the utility of country $i$ of deviation phase is given by

$$
u_{i}^{D}=A \kappa-\frac{239 \kappa^{2}}{288}-\frac{\kappa \theta}{3}
$$

for $i=b, c, j=c, b, j \neq i$. Inserting $u_{i}^{C}$ in (A3), $u_{i}^{D}$ in (A4) and $u_{i}^{N}$ in Eq.(13) into Eq. (16), we have Eq. (23).

Appendix E. We have

$$
u_{i}^{C}=\frac{5 \kappa^{2}}{9} \text { and } u_{i}^{N}=\frac{32 \kappa^{2}}{81}+\frac{5 \kappa \theta}{27}-\frac{7 \theta^{2}}{144}
$$

Then Assumption 1 comes from the following relationship:

$$
u_{i}^{C}-u_{i}^{N}=\frac{7 \theta^{2}}{144}-\frac{5 \theta \kappa}{27}+\frac{13 \kappa^{2}}{81}>0 \leftrightarrow 0<\theta<\frac{4 \kappa}{3}
$$

If we mention it precisely, the conditions for $u_{i}^{C}-u_{i}^{N}>0$ would be $0<\theta<4 \kappa / 3$ or $\theta>$ $52 \kappa / 21$. But if $\theta>52 \kappa / 21$, the scale of equalization transfer scheme $\theta(0<\theta<1)$ is larger than the total capital endowments $2 \kappa$, which is unrealistic. Hence, we exclude $\theta>52 \kappa / 21$ from the participation constraint condition.

Appendix F. When country $i(i=b, c)$ deviates from tax coordination, we obtain in the deviation phase:

$$
\begin{aligned}
t_{i}^{D}=\frac{9 \theta}{16}+\frac{7 \kappa}{12}, t_{j}^{C} & =\frac{4 \kappa}{3}, t_{a}^{C}=-\frac{2 \kappa}{3}, k_{i}^{D}=\frac{7 \kappa}{12}-\frac{3 \theta}{16}, \\
k_{j}^{D} & =\frac{5 \kappa}{24}+\frac{3 \theta}{32} \text { and } r^{D}=A-\frac{7 \kappa}{4}-\frac{3 \theta}{16}
\end{aligned}
$$


where $i=b, c, j=c, b, j \neq i$. Using (A5), we get

$$
\begin{gathered}
\frac{\partial\left(k_{i}^{D}\right)^{2}}{\partial \theta}=\frac{9 \theta}{128}-\frac{7 \kappa}{32}, \quad k_{i}^{D} \frac{\partial t_{i}^{D}}{\partial \theta}+t_{i}^{D} \frac{\partial k_{i}^{D}}{\partial \theta}=\frac{7 \kappa}{32}-\frac{27 \theta}{128} \\
\theta \frac{\partial\left(\frac{k_{i}^{D}+k_{j}^{D}}{2}-k_{i}^{D}\right)}{\partial \theta}=\frac{9 \theta}{64}, \text { and }\left(\frac{k_{i}^{D}+k_{j}^{D}}{2}-k_{i}^{D}\right)=-\frac{9 \theta}{64}\left(\frac{4 \kappa}{3}-\alpha\right) .
\end{gathered}
$$

Then, we have

$$
\frac{\partial\left(k_{i}^{D}\right)^{2}}{\partial \theta}+\theta \frac{\partial\left(\frac{k_{i}^{D}+k_{j}^{D}}{2}-k_{i}^{D}\right)}{\partial \theta}+k_{i}^{D} \frac{\partial t_{i}^{D}}{\partial \theta}+t_{i}^{D} \frac{\partial k_{i}^{D}}{\partial \theta}=0
$$

which is used to obtain Eq.(27).

\section{Reference}

Boadway, R. and Shah, A. (2007). Intergovernmental Fiscal Transfers: Principles and Practice. Washington, DC: World Bank.

Bucovetsky, S. (2009) An index of capital tax competition, International Tax and Public Finance 16, $727-752$.

Burbidge, J., J. DePater, G.M. Myers, and A. Sengupta. (1997). A coalition-formation approach to equilibrium federations and trading blocs, American Economic Review 87, 940-956.

Cardarelli, R., Taugourdeau, E., and Vidal, J.P. (2002). A repeated interactions model of tax competition, Journal of Public Economic Theory 4, 19-38.

Catenaro, M., and Vidal, J.P. (2006). Implicit tax co-ordination under repeated policy interactions, Recherches Economiques de Louvain 72, 1-17.

Itaya, J., Okamura, M., and Yamaguchi, C. (2008). Are regional asymmetries detrimental to tax coordination in a repeated game setting? Journal of Public Economics 92, 2403-2411.

Itaya, J., Okamura, M. and Yamaguchi, C. (2014), Partial tax coordination in a repeated game setting, European Journal of Political Economy 34, 263-278.

Itaya, J. and Yamaguchi, C. (2015), Does endogenous timing matter in implementing partial tax harmonization?, Discussion paper series A, no.286, Hokkaido University.

Itaya, J., Okamura, M. and Yamaguchi, C. (2016). Implementing partial tax harmonization in an asymmetric tax competition game with repeated interaction, Canadian Journal of Economics, in press.

Kächelein, H. (2004), Capital tax competition and partial cooperation: Welfare enhancing or not?, BERG working paper series on government and growth, No.51.

Kawachi, K. and Ogawa, H. (2006). Further analysis on public good provision in a repeated game setting. FinanzArchiv 62, 339-352.

Keen, M., and K.A. Konrad (2013) The theory of international tax competition and coordination, in A.J. Auerbach, R. Chetty, M. Feldstein, E. Saez (Eds.), Handbook of Public Economics 5, pp.257-328 (Chapter 5), Amsterdam: North-Holland.

Kiss, A. (2012), Minimum taxes and repeated tax competition, International Tax and Public Finance 19, 641-649.

Konrad, K.A. and G. Schjelderup. (1999), Fortress building in global tax competition, Journal of Urban Economics 46, 156-167.

Köthenbürger, M. (2002), Tax competition and fiscal equalization, International Tax and Public Finance 9, 391-408. 
Köthenbürger, M. (2005), Leviathans, Federal transfers, and the cartelization hypothesis, Public Choice 122, 449-465.

Köthenbürger, M. (2007), Ex-post redistribution in a federation: Implications for corrective policy, Journal of Public Economics 91, 481-496.

Marchand, M., Pestieau, P., and Sato, M. (2003), Can partial fiscal coordination be welfare worsening?: A model of tax competition, Journal of Urban Economics 54, 451-458.

Ogawa, H. and Wang, W. (2016), Asymmetric tax competition and fiscal equalization in a repeated game setting, International Review of Economics and Finance 41, 1-10.

Taugourdeau, E. (2004). Is cooperation always sustainable when regions differ in size?. Annals of Economics and Statistics 75/76, 173-185.

Vrijburg, H., and R.A. de Mooij (2009) Enhanced cooperation in an asymmetric model of tax competition, Tinbergen Institute Discussion Paper TI 2010-011/3.

Wang, W., Kawachi, K., and Ogawa, H. (2014). Fiscal transfer in a repeated interaction model of tax competition. FinanzArchiv 70, 556-566.

Wildasin, D.E. (1989) Interjurisdictional capital mobility: Fiscal externality and a corrective subsidy, Journal of Urban Economics 25, 193-212. 